\title{
Associations between microRNA (miR-25, miR-32, miR-125, and miR-222) polymorphisms and recurrent implantation failure in Korean women
}

\author{
Jeong Yong Lee ${ }^{\dagger}$, Eun Hee Ahn ${ }^{\dagger}$, Jung Oh Kim', Han Sung Park', Chang Soo Ryu' ${ }^{1}$ Ji Hyang Kim²,
} Young Ran Kim², Woo Sik Lee ${ }^{3^{*}}$ and Nam Keun Kim ${ }^{1 *}$ (D)

\begin{abstract}
Background: Recurrent implantation failure (RIF) is the failure of embryos to implant more than two times in a given individual. There is debate about a precise definition for RIF, but we consider more than two implantation failures for individuals who undergo in vitro fertilization-embryo transfer (IVF-ET) to constitute RIF. There are many potential reasons for RIF, including embryonic factors, immunological factors, uterine factors, coagulate factors, and genetic factors. Genetic variation has been suggested as one of the contributing factors leading to RIF, and a number of single-nucleotide polymorphisms (SNPs) have been reported to be associated with RIF. The recent elucidation of miRNA functions has provided new insight into the regulation of gene expression.

Methods: We investigated associations between polymorphisms in four miRNAs and RIF in 346 Korean women: 118 patients with RIF and 228 controls. We determined the genotypes of the miRNAs in the study participants by polymerase chain reaction-restriction fragment-length polymorphism (PCR-RFLP) analysis. We analyzed the effects of genotypes, allele combinations, and environmental and clinical factors on the risk of RIF.

Results: The miR-25 T/miR-125aT/miR-222G (odds ratio (OR), 0.528; 95\% confidence interval (Cl), 0.282-0.990; $P=$ 0.044) and miR-25 T/miR-125aT allele combinations were associated with a reduced risk of RIF. The miR-25T/miR32C/miR-125aC/miR-222T allele combination was associated with an increased risk of RIF. The miR-222GT+TT genotypes interacted with high prothrombin time $(\geq 12 \mathrm{~s})$ to increase the risk of RIF.

Conclusions: MicroRNA polymorphisms are significantly different between patients that experience RIF and healthy controls. Combinations of microRNA polymorphisms were associated with the risk of RIF. Interactions between environmental factors and genotypes increased the risk of RIF in Korean women.
\end{abstract}

Keyword: MicroRNA, Polymorphism, Recurrent implantation failure, Single nucleotide variation

\section{Introduction}

Recurrent implantation failure (RIF) is when implanted embryos repeatedly fail. There is debate about a precise definition for RIF [1-3], but we consider more than two implantation failures for individuals who undergo

\footnotetext{
* Correspondence: wooslee@cha.ac.kr; nkkim@cha.ac.kr

${ }^{\dagger}$ Jeong Yong Lee and Eun Hee Ahn contributed equally to this work.

${ }^{3}$ Department of Obstetrics and Gynecology, CHA Gangnam Medical Center,

School of Medicine, CHA University, Seoul 06135, South Korea

'Department of Biomedical Science, College of Life Science, CHA University,

Seongnam 13488, South Korea

Full list of author information is available at the end of the article
}

in vitro fertilization-embryo transfer (IVF-ET) to constitute RIF. Many potential reasons for RIF have been reported, including embryonic factors, immunological factors, uterine factors, coagulate factors, and genetic factors.

MicroRNAs (miRNAs) are small (approximately 1822 nucleotides), non-protein-coding RNAs that regulate gene expression by causing transcript degradation and translational repression $[4,5]$. Cellular processes, such as proliferation and apoptosis, are also regulated by miRNAs via complementary base-pair binding to $3^{\prime} \mathrm{UTR}$

(c) The Author(s). 2019 Open Access This article is distributed under the terms of the Creative Commons Attribution 4.0 International License (http://creativecommons.org/licenses/by/4.0/), which permits unrestricted use, distribution, and 
regions of mRNAs, resulting in mRNA degradation and translational repression [4]. One study that evaluated microRNA expression in patients with RIF discovered that 3800 genes could be regulated by only 13 microRNAs [5]. Another study reported that 313 genes were upregulated or downregulated in patients with RIF [6]. A study of IVF in rodents revealed that downregulation of the microRNA 199a-5p was associated with poor blastocyst development [7].

Maternal vascular development is very important in early pregnancy [8]. Angiogenesis plays a key role in corpus luteum development, embryo implantation, and placentation [8]. Because both angiogenesis and vasculogenesis are essential during early pregnancy for the proper conditioning of the uterus and placenta, high expression levels of VEGF and KDR are required [9]. Growth factors such as VEGF and their respective receptors drive the angiogenic process $[8,9]$, while other proteins, such as fibrinogen, also have an effect [8].

VEGF functions to increase cell proliferation, migration, and differentiation and is highly polymorphic [10]. VEGF has been associated with RIF after IVF-ET with intracytoplasmic sperm injection [11]. Abnormal maternal expression of VEGF may be associated with abnormal angiogenesis during implantation [12]. A previous study suggested that miRNAs regulate VEGF expression [13], implicating miRNAs as a possible cause of implantation failure [14]. KDR is a VEGF receptor that plays an essential role in angiogenesis in the placenta and fetus [15]. Additionally, in vivo and in vitro studies showed that KDR disruption can cause defects in fetal development and angiogenesis [16]. During pregnancy, following fibrinogen-fibrin conversion, the levels of thrombin and markers of coagulation and fibrinolytic activation are increased [16, 17].

Research shows that miRNAs affecting the expression of certain genes are associated with various diseases [18, 19] as well as with ovarian function [20, 21]. A recent study reported that miRNAs are involved in the uterine condition and affect other stages of pregnancy, such as implantation [22]. These findings suggest other possibly important roles of miRNAs in reproduction. We selected four miRNA polymorphisms (miR-25 rs1527423 T>C, miR-32 rs7041716 C>A, miR-125a rs12976445 C>T, and miR-222 rs34678647 G>T) that were previously shown to impact the regulation of genes related to vascular function, thrombosis, and angiogenesis, all of which have been shown to be associated with unexplained female infertility [23, 24]. Each of these selected polymorphisms occurs in miRNAs that bind to the 3'UTRs of VEGF, KDR, and fibrinogen mRNAs. Thus, we assessed the frequencies of the four miRNA polymorphisms in Korean women and analyzed their associations with the risk of RIF.

\section{Results}

We investigated the relationships between polymorphisms in each miRNA $(m i R-25 \mathrm{~T}>\mathrm{C}, m i R-32 \mathrm{C}>\mathrm{A}, m i R-$ $125 \mathrm{C}>\mathrm{T}$, and $m i R-222 \mathrm{G}>\mathrm{T}$ ) and RIF in Korean women. The demographic clinical profiles of the participants are presented in Table 1 . The controls and the patients with RIF were matched by age and gender. The PT, aPTT, and total cholesterol levels were significantly higher $(P<$ $0.05)$ in the controls than in the patients with RIF. The genotype frequencies of the patients and controls are shown in Table 2. There were no significant differences in genotype frequencies between the patients and the controls. The reference genotypes of miR-25, miR-32, miR-125a, and miR-222 were present in $78.5 \%, 82.0 \%$, $74.6 \%$, and $58.3 \%$ of the controls and $79.7 \%, 79.7 \%$, $83.1 \%$, and $52.5 \%$ of the patients with RIF, respectively. The genotypes of all four miRNAs were in HWE.

To identify associations between allele combinations and RIF risk, we analyzed combinations of four polymorphisms of the miRNA genes (Table 3). The combinations $m i R-25 \mathrm{~T} / m i R-125 a \mathrm{~T} / m i R-222 \mathrm{G}$ (AOR, 0.528; 95\% CI, $0.282-0.990 ; P=0.044)$ and $m i R-25 \mathrm{~T} / m i R-125 a \mathrm{~T}$ (AOR, 0.510; 95\% CI, 0.285-0.913; $P=0.022$ ) were associated with a lower risk of RIF. By contrast, the combinations $\quad m i R-25 \mathrm{~T} / m i R-32 \mathrm{C} / m i R-125 a \mathrm{C} / m i R-222 \mathrm{~T}$ (AOR, 1.496; 95\% CI, 1.000-2.237; $P=0.049$ ) and $m i R-$ $25 \mathrm{~T} / m i R-32 \mathrm{C} / m i R-222 \mathrm{~T}$ (AOR, 1.585; 95\% CI, $1.071-$ $2.345 ; P=0.021)$ were associated with a greater risk of RIF.

We analyzed the interactions between coagulation factors and the miRNAs (Table 4). There were significant differences in PT, aPTT, uric acid, BUN, creatinine, and LH levels between RIF and control patients $(P<0.05$ for each comparison). We looked for synergistic interactions between miRNA polymorphisms and environmental factors. The miR-222GT+TT genotypes interacted significantly with blood coagulation factors to increase the risk of RIF $(P<0.05)$; individuals with PT in the upper quartile (PT $\geq 12 \mathrm{~s}$ ) and those with the $m i R-222 \mathrm{GT}+\mathrm{TT}$ genotypes had a dramatically increased risk of RIF.

We performed ANOVA for each group between miRNA genotypes and the clinical parameters. As shown in Table 5, creatinine levels decreased when miR-222 polymorphisms changed in control women $(P<0.05)$. Furthermore, FSH levels were shown to increase with specific miR-222 polymorphisms in RIF patients (Table 6). Therefore, creatinine and FSH levels may be dependent on miRNA-222 polymorphisms.

\section{Discussion}

We examined the interplay between miRNA polymorphisms $\quad(m i R-25 \quad$ rs1527423 $\quad \mathrm{T}>\mathrm{C} / m i R-32 \quad$ rs7041716 $\mathrm{C}>\mathrm{A} / m i R-125 \mathrm{a}$ rs12976445 $\mathrm{C}>\mathrm{T} / m i R-222$ rs34678647 $\mathrm{G}>\mathrm{T}$ ) and RIF risk. First, we compared clinical profiles 
Table 1 Clinical profiles of patients with RIF and controls individuals

\begin{tabular}{|c|c|c|c|}
\hline Characteristics & $\begin{array}{l}\text { Controls } \\
(n=228)\end{array}$ & $\begin{array}{l}\text { RIF } \\
(n=118)\end{array}$ & $P$ value \\
\hline Age (years) & $33.8 \pm 3.26$ & $34.1 \pm 3.21$ & 0.296 \\
\hline $\mathrm{BMI}\left(\mathrm{kg} / \mathrm{m}^{2}\right)$ & $21.7 \pm 3.31$ & $21.0 \pm 2.76$ & 0.084 \\
\hline Previous implantation failure (n) & 0 & 112 & N/A \\
\hline Live births (n) & 1.77 & 0 & N/A \\
\hline Mean gestational age (weeks) & $39.2 \pm 1.69$ & 0 & N/A \\
\hline $\mathrm{PT}(\mathrm{s})$ & $11.3 \pm 3.12$ & $11.1 \pm 1.49$ & $0.0003^{+}$ \\
\hline aPTT (s) & $30.8 \pm 4.62$ & $29.2 \pm 3.42$ & $0.024^{+}$ \\
\hline $\operatorname{PLT}\left(10^{3} / \mu \mathrm{l}\right)$ & $243.3 \pm 59.99$ & $233.9 \pm 58.49$ & 0.186 \\
\hline Homocysteine ( $\mu \mathrm{mol} / \mathrm{L})$ & N/A & $6.6 \pm 1.34$ & N/A \\
\hline Folate $(\mathrm{mg} / \mathrm{ml})$ & $15.0 \pm 8.97$ & $15.6 \pm 11.29$ & 0.865 \\
\hline Total cholesterol (mg/dl) & $229.4 \pm 90.57$ & $189.1 \pm 44.68$ & $0.062^{\dagger}$ \\
\hline Uric acid (mg/dl) & N/A & $3.9 \pm 0.96$ & N/A \\
\hline $\mathrm{BUN}(\mathrm{mg} / \mathrm{dl})$ & $8.1 \pm 1.83$ & $10.3 \pm 2.82$ & $<0.0001^{\dagger}$ \\
\hline Creatinine (mg/dl) & $0.7 \pm 0.08$ & $0.8 \pm 0.10$ & $<0.0001$ \\
\hline E2 (Basal) & $26.3 \pm 14.72$ & $2465.2 \pm 2457.73$ & $<0.0001^{\dagger}$ \\
\hline $\mathrm{TSH}(\mathrm{mU} / \mathrm{L})$ & N/A & $2.3 \pm 1.43$ & N/A \\
\hline $\mathrm{FSH}(\mathrm{mU} / \mathrm{L})$ & $8.2 \pm 2.85$ & $8.7 \pm 4.52$ & $0.784+$ \\
\hline $\mathrm{LH}(\mathrm{mU} / \mathrm{L})$ & $3.3 \pm 1.76$ & $4.8 \pm 2.29$ & $<0.0001^{\dagger}$ \\
\hline Prolactin $(\mathrm{ng} / \mathrm{mL})$ & N/A & $12.6 \pm 6.21$ & N/A \\
\hline $\operatorname{WBC}\left(10^{3} / \mu \mathrm{l}\right)$ & N/A & $7.2 \pm 2.86$ & N/A \\
\hline $\mathrm{Hgb}(\mathrm{g} / \mathrm{dl})$ & N/A & $12.6 \pm 1.41$ & N/A \\
\hline CD3 (pan T) & N/A & $66.2 \pm 11.28$ & N/A \\
\hline CD4 (helper T) & N/A & $33.9 \pm 8.68$ & N/A \\
\hline CD8 (suppressor) & N/A & $29.0 \pm 7.85$ & N/A \\
\hline CD19 (B-cell) & N/A & $11.0 \pm 4.45$ & N/A \\
\hline CD56 (NK cell) & N/A & $20.0 \pm 9.56$ & N/A \\
\hline
\end{tabular}

Italicized text indicates significant $P$ values. Data are presented as the mean \pm standard deviation

$R I F$, recurrent implantation failure; $B M I$, body mass index; $P T$, prothrombin time; $a P T T$, activated partial thromboplastin time; $P L T$, platelet count; $B U N$, blood urea nitrogen; E2, estradiol; $T S H$, thyroid stimulating hormone; $F S H$, follicle-stimulating hormone; $L H$, luteinizing hormone; WBC, white blood cell; $H g b$, hemoglobin

${ }^{\dagger}$ Mann-Whitney test

between 228 healthy control individuals and 118 patients with RIF. There were significant differences in PT, aPTT, uric acid, BUN, creatinine, and LH between the patients with RIF and the controls $(P<0.05$ for each comparison). There were no significant differences in the genotypic frequencies of any of the miRNA polymorphisms, even among subgroups, between the patients and the controls. Analysis of allele combinations among the miRNAs suggested that the combinations $m i R-25 \mathrm{~T} / m i R-125 a \mathrm{~T} / m i R-222 \mathrm{G}$ and $m i R-25 \mathrm{~T} / m i R-125 a \mathrm{~T}$ had protective effects against RIF $(P<0.044$ and $P<0.022$, respectively). Also, miR-222 rs34678647 interacted significantly with blood coagulation factor (PT and aPTT) values in the upper quartile. Alteration of the functional activity of blood coagulation factors might influence implantation [25]. Several studies have suggested that thrombophilia might increase the risk of implantation failure [16].

In this study, we looked for differences in clinical parameters between RIF and control patients and also between different miRNA genotypes. We found no differences in PT, aPTT, or PLT between RIF and control patients or among the genotypes.

Many miRNAs have important roles in diverse cellular processes [23], including the regulation of molecular pathways, adhesive junctions, and cell adhesion in patients with RIF [5]. MicroRNA-181 inhibits embryo implantation in vivo by inhibiting the expression of leukemia inhibitory factor [24]. MicroRNAs play important roles in the regulation of genes that influence endometrial receptivity [26]. Several studies reported evidence that microRNAs are relevant to RIF in humans. MicroRNA-30b/d and microRNA-494 were shown to be 


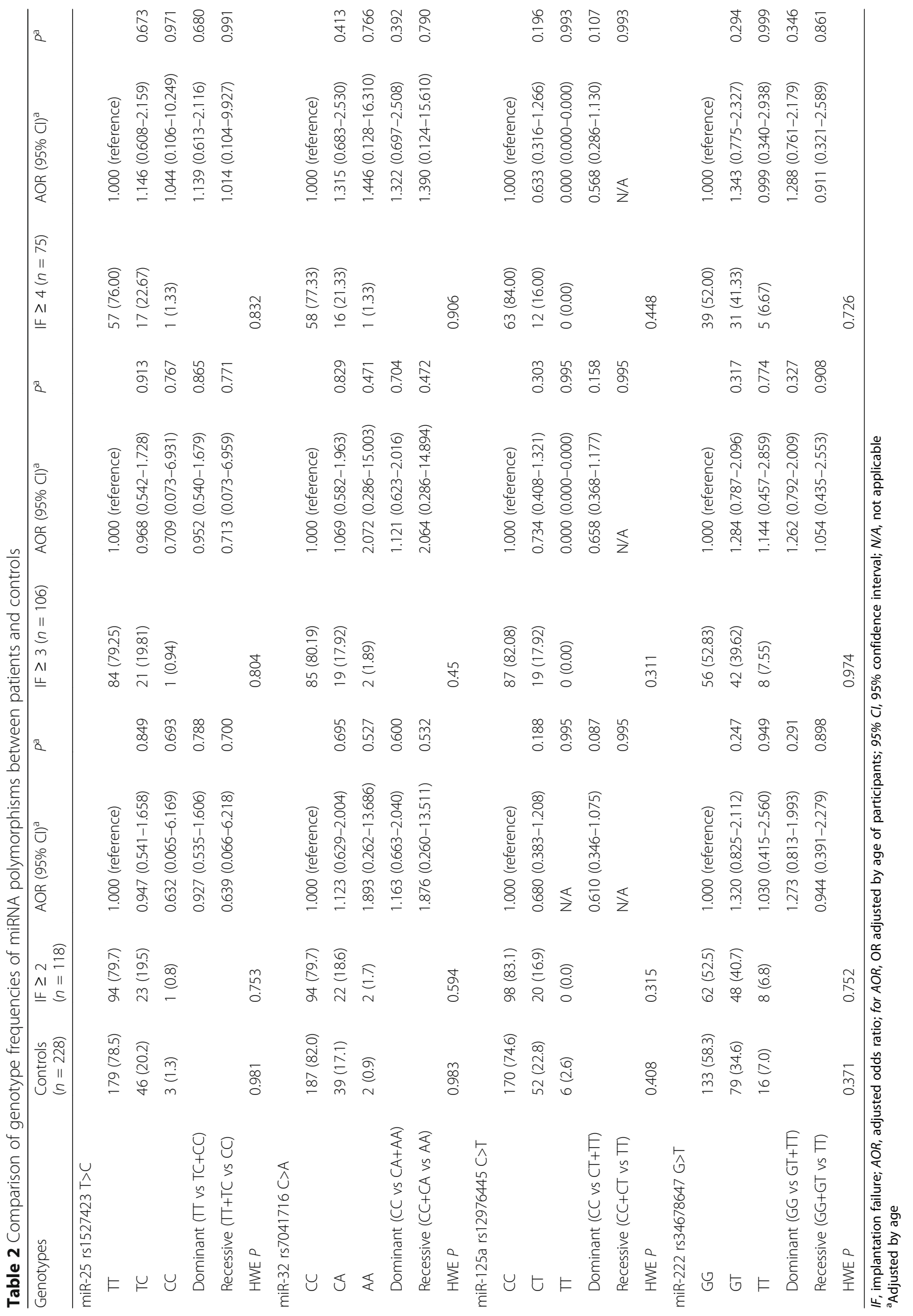


Table 3 Allele combination analysis for the miRNA polymorphisms in patients and controls using MDR

\begin{tabular}{|c|c|c|c|c|c|}
\hline Allele combinations & $\begin{array}{l}\text { Overall } \\
(2 n=692)\end{array}$ & $\begin{array}{l}\text { Controls } \\
(2 n=456)\end{array}$ & $\begin{array}{l}\text { RIF } \\
(2 n=236)\end{array}$ & OR $(95 \% \mathrm{Cl})$ & $P^{a}$ \\
\hline \multicolumn{6}{|c|}{ miR-25 T>C/ miR-32 C>A/ miR-125aC>T/ miR-222G $>\mathrm{T}$} \\
\hline T-C-C-G & 0.5035 & 0.5203 & 0.4841 & 1.000 (reference) & \\
\hline $\mathrm{T}-\mathrm{C}-\mathrm{C}-\mathrm{T}$ & 0.2081 & 0.1798 & 0.2482 & $1.496(1.000-2.237)$ & 0.049 \\
\hline T-C-T-G & 0.0884 & 0.1026 & 0.0566 & $0.575(0.299-1.106)$ & 0.094 \\
\hline T-C-T-T & 0.0047 & 0.0059 & 0.0065 & $1.386(0.228-8.414)$ & 0.662 \\
\hline T-A-C-G & 0.0563 & 0.0436 & 0.0797 & $1.975(1.014-3.847)$ & 0.042 \\
\hline C-C-C-G & 0.0653 & 0.0527 & 0.0753 & $1.559(0.813-2.989)$ & 0.178 \\
\hline C-C-C-T & 0.0124 & 0.0260 & 0.0000 & $0.083(0.005-1.415)$ & 0.022 \\
\hline C-C-T-G & 0.0136 & 0.0140 & 0.0191 & $1.732(0.518-5.798)$ & 0.352 \\
\hline \multicolumn{6}{|c|}{$\mathrm{miR}-25 \mathrm{~T}>\mathrm{C} / \mathrm{miR}-125 \mathrm{aC}>\mathrm{T} / \mathrm{miR}-222 \mathrm{G}>\mathrm{T}$} \\
\hline $\mathrm{T}-\mathrm{C}-\mathrm{G}$ & 0.5598 & 0.5617 & 0.5635 & 1.000 (reference) & \\
\hline $\mathrm{T}-\mathrm{C}-\mathrm{T}$ & 0.2253 & 0.2013 & 0.2650 & $1.318(0.899-1.933)$ & 0.157 \\
\hline T-T-G & 0.0949 & 0.1120 & 0.0594 & $0.528(0.282-0.990)$ & 0.044 \\
\hline T-T-T & 0.0087 & 0.0110 & 0.0062 & $0.385(0.045-3.331)$ & 0.668 \\
\hline C-C-G & 0.0783 & 0.0691 & 0.0868 & $1.203(0.662-2.185)$ & 0.543 \\
\hline $\mathrm{C}-\mathrm{C}-\mathrm{T}$ & 0.0152 & 0.0276 & 0.0000 & $0.071(0.004-1.207)$ & 0.006 \\
\hline C-T-G & 0.0141 & 0.0138 & 0.0191 & $1.604(0.481-5.355)$ & 0.523 \\
\hline C-T-T & 0.0037 & 0.0036 & 0.0000 & $0.384(0.018-8.068)$ & 0.550 \\
\hline \multicolumn{6}{|c|}{ miR-25 T>C/ miR-32 C>A/ miR-222 G>T } \\
\hline $\mathrm{T}-\mathrm{C}-\mathrm{G}$ & 0.5909 & 0.6224 & 0.5405 & 1.000 (reference) & \\
\hline $\mathrm{T}-\mathrm{C}-\mathrm{T}$ & 0.2128 & 0.1841 & 0.2554 & $1.585(1.071-2.345)$ & 0.021 \\
\hline T-A-G & 0.0643 & 0.0538 & 0.0824 & $1.686(0.896-3.173)$ & 0.102 \\
\hline T-A-T & 0.0207 & 0.0256 & 0.0158 & $0.740(0.234-2.338)$ & 0.785 \\
\hline$C-C-G$ & 0.0788 & 0.0665 & 0.0940 & $1.627(0.903-2.931)$ & 0.103 \\
\hline $\mathrm{C}-\mathrm{C}-\mathrm{T}$ & 0.0178 & 0.0327 & 0.0000 & $0.071(0.004-1.204)$ & 0.007 \\
\hline$C-A-G$ & 0.0131 & 0.0139 & 0.0119 & $1.109(0.273-4.507)$ & 1.000 \\
\hline C-A-T & 0.0016 & 0.0010 & 0.0000 & N/A & N/A \\
\hline \multicolumn{6}{|c|}{ miR-25 T>C/ miR-222G $>\mathrm{T}$} \\
\hline T-G & 0.6545 & 0.6739 & 0.6229 & 1.000 (reference) & \\
\hline $\mathrm{T}-\mathrm{T}$ & 0.2342 & 0.2121 & 0.2712 & 1.378 (0.950-1.999) & 0.090 \\
\hline C-G & 0.0926 & 0.0827 & 0.1059 & $1.374(0.799-2.362)$ & 0.249 \\
\hline$C-T$ & 0.0187 & 0.0313 & 0.0000 & $0.072(0.004-1.214)$ & 0.007 \\
\hline \multicolumn{6}{|c|}{ miR-25 T>C/ miR-125aC>T } \\
\hline $\mathrm{T}-\mathrm{C}$ & 0.7844 & 0.7625 & 0.8277 & 1.000 (reference) & \\
\hline $\mathrm{T}-\mathrm{T}$ & 0.1043 & 0.1235 & 0.0663 & $0.510(0.285-0.913)$ & 0.022 \\
\hline $\mathrm{C}-\mathrm{C}$ & 0.0942 & 0.0972 & 0.0875 & $0.852(0.492-1.474)$ & 0.566 \\
\hline C-T & 0.0170 & 0.0169 & 0.0184 & $0.892(0.265-3.002)$ & 1.000 \\
\hline
\end{tabular}

Italicized text indicates significant $P$ values

$R I F$, recurrent implantation failure; $O R$, odds ratio; $95 \% \mathrm{Cl}, 95 \%$ confidence interval; $N / A$, not applicable; $M D R$, multi-dimensional reduction

${ }^{\mathrm{a}}$ Fisher's exact test

differentially regulated in receptive endometrium [27]. Moreover, microRNA-30b was upregulated in patients with RIF [26]. Furthermore, microRNA-374 was reported to activate the $\mathrm{Wnt} / \beta$-catenin pathway, which is associated with implantation [28]. The four miRNAs that we investigated are known to bind the 3'UTRs of fibrinogen, VEGF, and KDR [13], all of which affect implantation [11].

We predicted miRNA targets using miRBase (http:// www.mirbase.org/) and TargetScan (http://www.targetscan. 


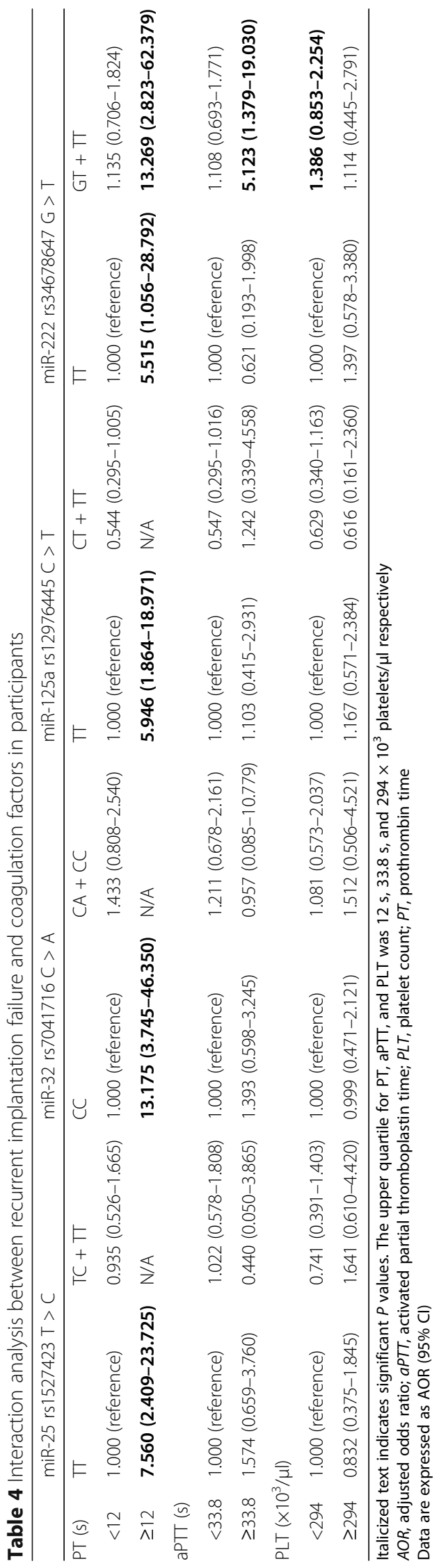




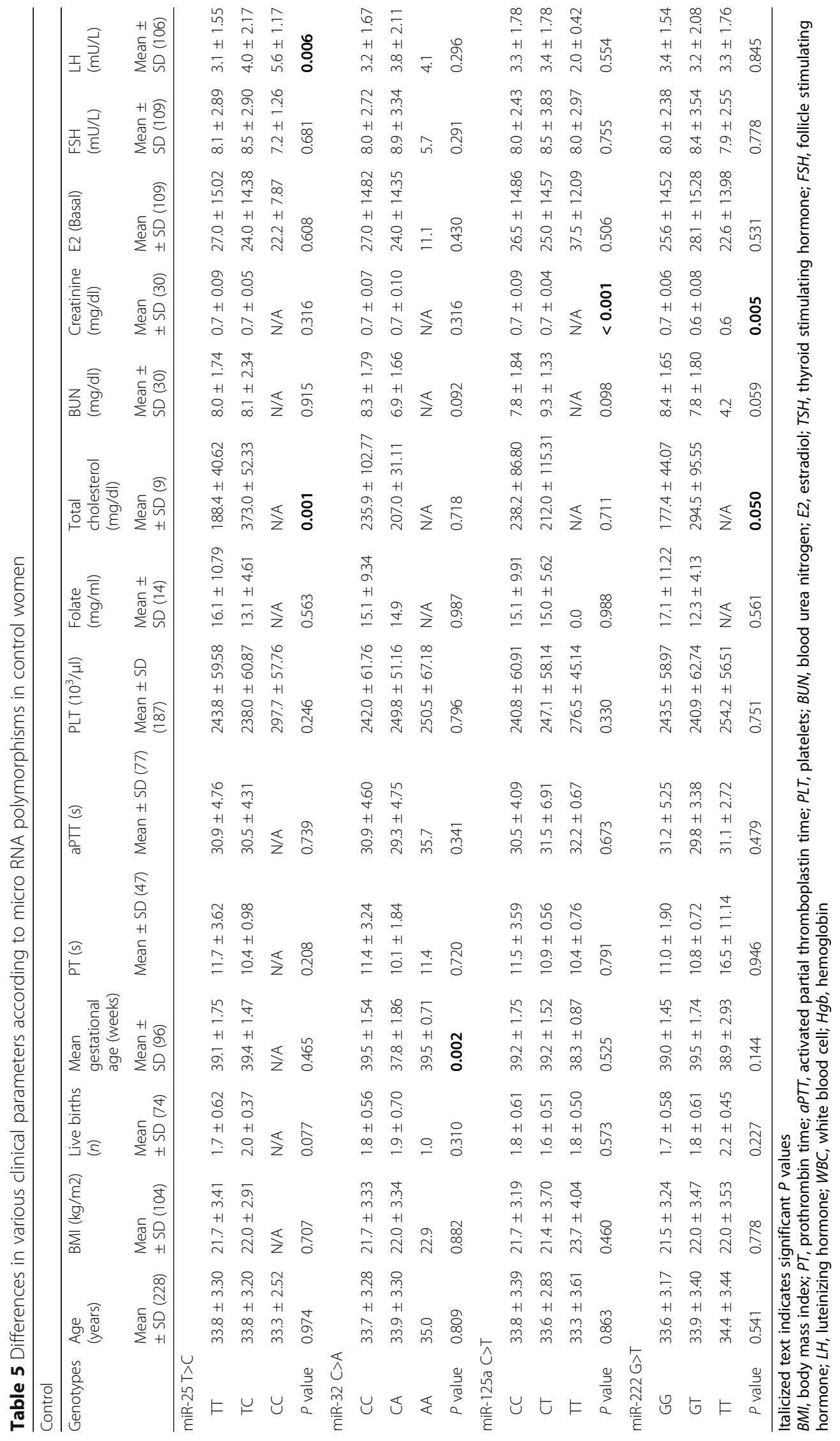




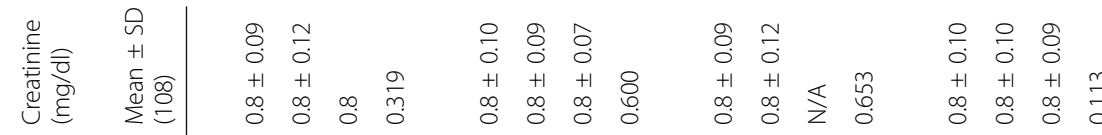

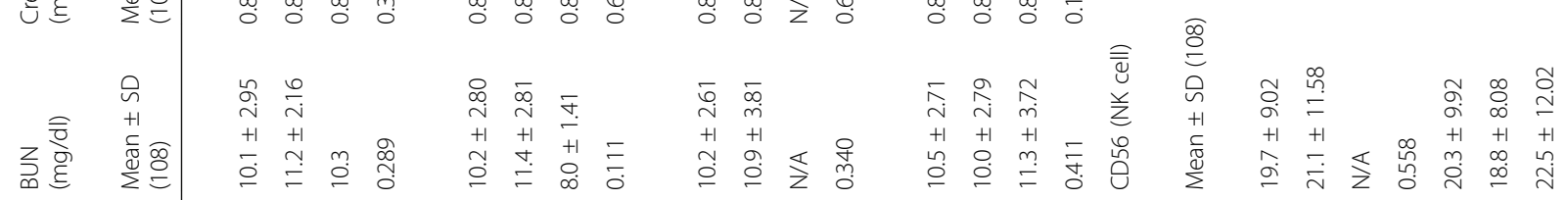

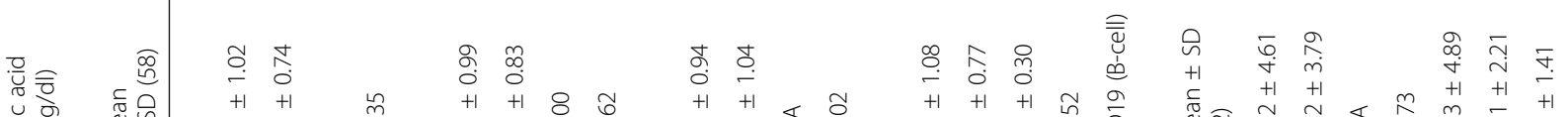

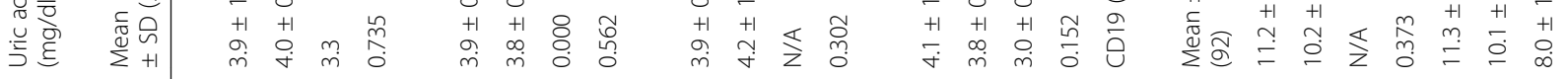

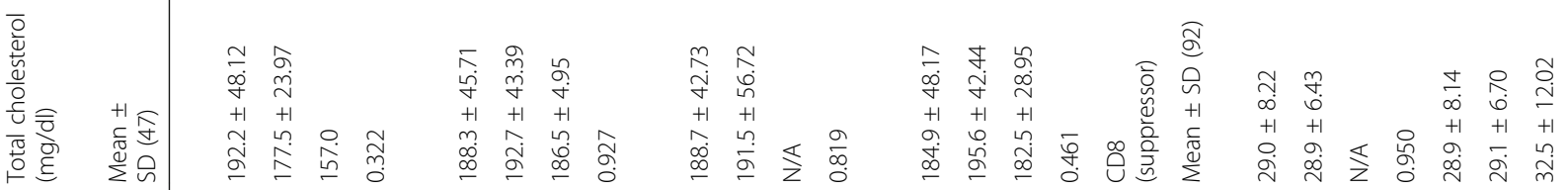

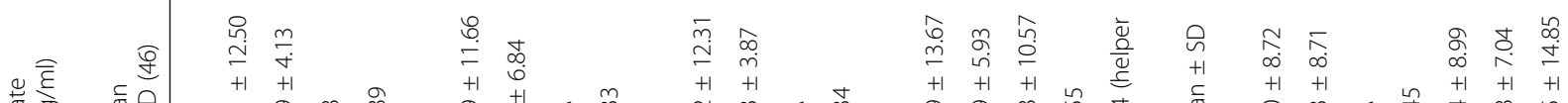

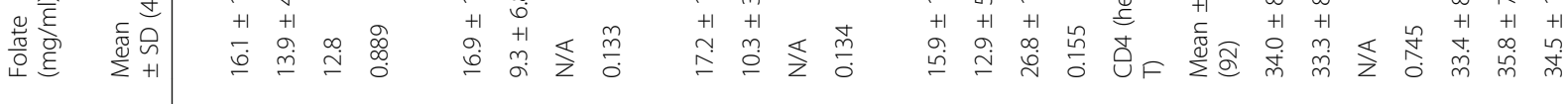

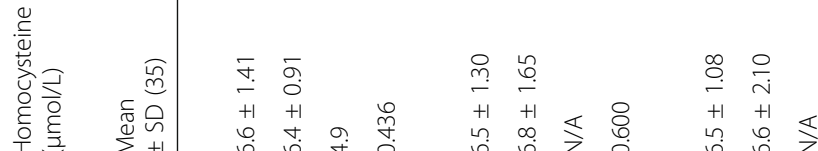

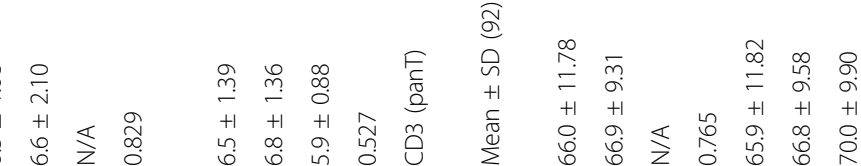

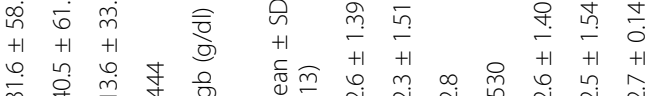

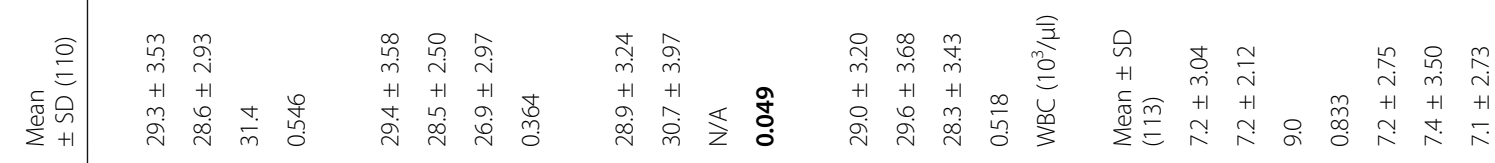

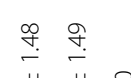

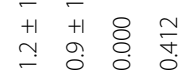

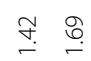

ֻูป

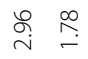

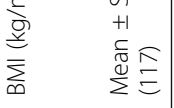

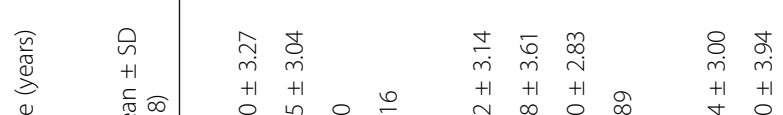


Lee et al. Human Genomics

(2019) 13:68

Page 9 of 13

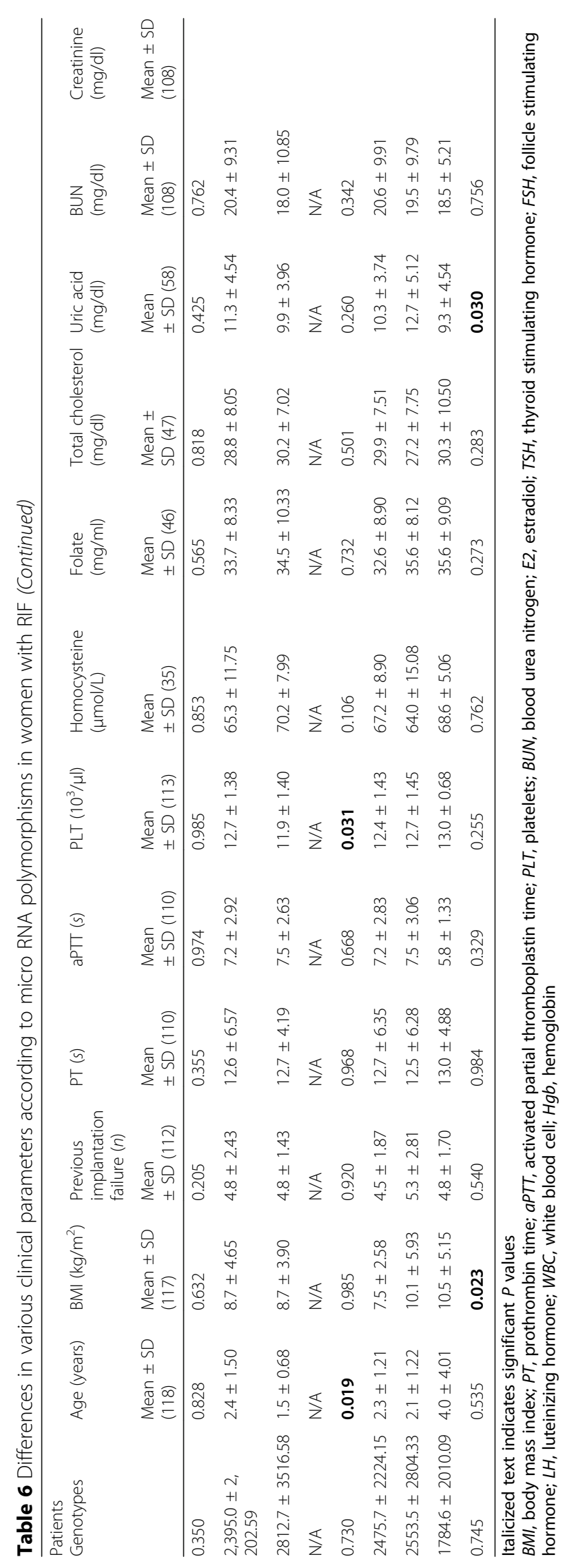


org/vert_72). We found that $m i R-25$ and $m i R-32$ bind fibrinogen, which plays an important role in the coagulation process [29]. The mature form of $m i R-125 a-3 p$ binds to VEGF. Altered VEGF function affects the occurrence of diseases such as breast cancer and coronary artery disease and is also associated with RPL [14, 30]. VEGF plays important roles in embryo implantation, vasculogenesis, and angiogenesis in tumor development and early gestation [8, 31]. Inactivation of a single VEGF allele in mice results in embryonic lethality and defects in several organs [15]. KDR (VEGFR2) is a VEGF receptor that may play an important role in angiogenesis and vascular development during the early stages of pregnancy [32]. The VEGF system is involved in the generation of hemangioblasts in embryos [33]. In mice, downregulation of VEGF or its two receptors results in fetal death in utero [14]. In our previous study, the VEGF and VEGFR genes were associated with an increased risk of colorectal cancer [34]. Angiogenesis may be altered via the VEGF-VEGFR pathway through decreased VEGF and VEGFR expression, resulting from an increased number of miRNA polymorphisms with high binding affinities for VEGF and VEGFR mRNAs [4, 13, 35].

In our previous study, miR-608 and miR-1302 affected the risk of RIF through their effects on coagulation factors [36]. Our present results further support the hypothesis that microRNAs associated with coagulation factors can increase the risk of RIF. In particular, prothrombin time (PT) was associated with certain microRNA polymorphisms (Table 4), suggesting that alteration of blood coagulation factors might affect implantation and also pregnancy.

A previous study reported that high FSH levels after IVF can reduce implantation rates in young women [37]. We found that the miR-222G $>\mathrm{T}$ mutation was associated with FSH levels (Table 6). Those results provide evidence that microRNAs can affect FSH levels, providing another potential mechanism by which microRNAs might affect implantation.

Women with RIF have significantly elevated numbers of NK cells that play a role in female reproductive performance [30, 31]. Uterine NK cells are important in pregnancy, especially in processes involving angiogenesis such as placentation [38]. In rodents, decidual natural killer (dNK) cell numbers are increased in a VEGFabundant environment, and dNK cells express multiple angiogenic and chemokine factors in humans [39, 40]. Furthermore, dNK cells make many factors that are abundant in mammalian tissues, such as VEGF and IL-8.

Sex hormones, such as estrogen and progesterone, contribute to immune tolerance of the early pregnancy environment. Estrogen has three different forms: estrogen, estradiol (E2), and estriol. In a previous report, E2 levels were correlated with levels of IL-35, the main cytokine that maintains immune tolerance. IL-35 levels are decreased in patients with a history of recurrent spontaneous abortions [41]. E2 also stimulates $\mathrm{CD} 4^{+} \mathrm{T}$ cells that produce inhibitory cytokines such as IL-35, TGF-b, and IL-10 [41]. In our study, patients with RIF had higher E2 values than controls.

$\mathrm{T}$ regulatory (Treg) cells have potent immunesuppressive activity, and the maintenance of immune suppression is important during pregnancy $[42,43]$. The numbers of $\mathrm{CD} 4^{+}$regulatory $\mathrm{T}$ cells are increased in the blood and lymph of pregnant rodents [44]. Human decidual tissue also shows increased numbers of $\mathrm{CD} 4^{+} \mathrm{T}$ cells [43]. Women who have experienced miscarriage have reduced numbers of Treg cells, including $\mathrm{CD} 4^{+}$ cells, in their blood compared with women who experience healthy pregnancies.

Circulating blood VEGF levels may be linked to several NK cell variables, activated NK cells, or NK cytotoxicity [45]. The possibility of a link between NK cells and reproductive outcomes is one of the most controversial issues in reproductive medicine [46]. It is possible that elevated VEGF levels disrupt normal angiogenesis, leading to disturbed vascular architecture [39]. Women with RIF were indeed found to have significantly increased levels of VEGF in their plasma [45].

Many microRNAs are used to screen for specific diseases and also as tools for therapy selection [40]. The microRNAs used in our study might be used biomarkers to assist RIF diagnosis in the future. Pregnancy-related microRNAs might also be used in therapeutic strategies involving the addition of microRNA mimics or antimicroRNAs [47]. The development of microRNA-based therapies will require advanced drug delivery systems that can carry microparticles as a cargo [48].

There are several limitations to our study. First, it remains unclear how miRNA polymorphisms affect RIF. We only focused on SNPs in four miRNAs and tried to discover how those SNPs may interact with other factors to influence the occurrence of RIF. Many factors contribute to pregnancy failure, however, and the genotypic frequencies were not enough to explain why implantation failure occurred repeatedly. Second, our study was limited to Korean women, so results may vary in women of other nations or ethnic groups. Third, we did not examine the expression of each miRNA in tissues. It is known that miRNAs bind to the 3'UTR of their target genes to inhibit them, and each miRNA polymorphism could affect their target gene expression. Therefore, because we collected blood samples, any tissue-specific factors such as microRNA or clinical parameter that may affect RIF occurrence may not be considered. Fourth, our sample size was small, and a larger sample size is required to confirm our results. To further verify our findings, future studies should use a larger population size and include additional ethnic groups. 


\section{Conclusion}

We analyzed the association between RIF risk and miRNA (miR-25, miR-32, miR-125, miR-222) polymorphisms. The genotype frequencies of each microRNAs did not significantly differ between patients with RIF and controls, but specific allele combinations interacted with clinical parameters to increase the risk of RIF.

\section{Materials and Methods}

\section{Study population}

Blood samples were obtained from 118 females with RIF and 228 healthy female controls. All study samples were collected from the Department of Obstetrics and Gynecology of CHA Bundang Medical Center (Seongnam, South Korea) between March 2010 and December 2012. We defined RIF as the failure to achieve pregnancy following the completion of two fresh IVF-ET cycles with one or two good quality embryos. Each transferred embryo was cleaved into more than 10 cells. Fourteen days after, all RIF patients' serum human chorionic gonadotrophin (hCG) concentrations were less than $5 \mathrm{U} /$ $\mathrm{ml}$. Individuals who were diagnosed with RIF due to anatomical, chromosomal, hormonal, infectious, autoimmune, or thrombotic causes were excluded from the study. Anatomical abnormalities were evaluated using several imaging modalities, including sonography, hysterosalpingogram, hysteroscopy, computerized tomography, and magnetic resonance imaging. Karyotyping was conducted using standard protocols to assess chromosomal abnormalities. We excluded hormonal causes of RIF, including hyperprolactinemia, luteal insufficiency, and thyroid disease, by measuring the concentrations of prolactin (PRL), thyroid-stimulating hormone (TSH), free thyroxine, follicle-stimulating hormone (FSH), luteinizing hormone (LH), estradiol (E2), and progesterone in samples of peripheral blood. To exclude lupus and antiphospholipid syndrome as autoimmune causes of RIF, we examined lupus anticoagulant and anticardiolipin antibodies according to the protocols of a previous study [49]. We evaluated thrombophilia by testing for protein $\mathrm{C}$ and $\mathrm{S}$ deficiencies and the presence of anti- $\alpha 2$ glycoprotein antibodies using methods described in a previous study [50].

\section{Genotype analysis}

Genomic DNA was extracted from whole blood using the G-DEX II Genomic DNA Extraction kit (Intron Biotechnology Inc., Seongnam, Korea). The DNA was diluted to $100 \mathrm{ng} / \mu \mathrm{l}$ with $1 \times \mathrm{TE}$ (Tris-EDTA) buffer, and then $1 \mu \mathrm{l}$ from each sample was used to amplify polymorphisms. All PCR experiments were performed using an AccuPower HotStart PCR PreMix (Bioneer Corporation, Daejeon, Korea). Genotyping analysis was performed by polymerase chain reaction-restriction fragment-length polymorphism (PCR-RFLP) [51] analysis with previously published primers [19]. The primers and restriction enzymes are shown in Additional file 1: Table S1.

\section{Assessment of blood coagulation status}

The platelet count (PLT), white blood cells (WBC), and hemoglobin $(\mathrm{Hgb})$ levels were measured using the Sysmex XE 2100 Automated Hematology System (Sysmex Corporation, Kobe, Japan). An ACL TOP automated photo-optical coagulometer (Mitsubishi Chemical Medience, Tokyo, Japan) was used to measure the prothrombin time (PT) and the activated partial thromboplastin time (aPTT).

\section{Statistical analysis}

Multivariate logistic regression was used to compare the differences in genotype and haplotype frequencies between the patients with RIF and the controls. Allelic frequencies were assessed for Hardy-Weinberg equilibrium (HWE) using $P<0.05$ as the significance threshold. We used adjusted odds ratios (AORs) and 95\% confidence intervals to assess the associations between different genotypes and RIF. $P<0.05$ was considered to indicate statistically significant differences. Differences in hormone concentrations (E2, FSH, LH, PRL, and TSH) were evaluated in accordance with miRNA genotypes and alleles using independent two-sample $t$ tests or one-way analysis of variance with a post hoc Scheffé test for all pairwise comparisons, as appropriate. Data are presented as the mean \pm standard deviation. Statistical analyses were performed using GraphPad Prism version 4.0 (GraphPad Software, Inc., La Jolla, CA, USA) and StatsDirect version 2.4.4 (StatsDirect Ltd., Altrincham, UK).

\section{Supplementary information}

Supplementary information accompanies this paper at https://doi.org/10. 1186/s40246-019-0246-y.

Additional file 1: Table S1. Details of miRNA polymorphisms for PCRRFLP analysis.

\section{Abbreviations}

RIF: Recurrent implantation failure; SNP: Single nucleotide polymorphism; IVF$\mathrm{ET}$ : In vitro fertilization-embryo transfer; PCR-RFLP: Polymerase chain reactionrestriction fragment-length polymorphism; OR: Odds ratio; miRNA: Micro RNA; PRL: Prolactin; TSH: Thyroid-stimulating hormone; FSH: Folliclestimulating hormone; LH: Luteinizing hormone; E2: Estradiol; HWE: HardyWeinberg equilibrium; PT: Prothrombin time; aPTT: Activated partial thromboplastin time

\section{Acknowledgements}

Not applicable.

Authors' contributions

WSL, EHA, and NKK designed the study. JHK, EHA, YRK, and WSL collected the sample and development of methodology. JYL, HSP, CSR, and EHA collected data. JYL and JOK conducted analysis and interpreted results. JYL 
drafted the manuscript. All authors reviewed and revised the final manuscript. All authors read and approved the final manuscript.

\section{Funding}

This work was supported by a grant of the Korea Healthcare Technology Research \& Development Project, Ministry for Health \& Welfare Affairs, Republic of Korea (HI18C1999).

\section{Availability of data and materials}

The datasets used and/or analyzed during the current study are available from the corresponding author on reasonable request.

\section{Ethics approval and consent to participate}

The study population consisted of participants recruited from the Department of Obstetrics and Gynecology of CHA Bundang Medical Center, CHA University (Seongnam-si, Korea) between March 2010 and December 2012. The Institutional Review Board of CHA Bundang Medical Center reviewed and approved the study on 23 February 2010 (reference no. PBC09-120). Informed consent was obtained from all participants.

\section{Consent for publication}

Not applicable.

\section{Competing interests}

The authors declare that they have no competing interests

\section{Author details}

${ }^{1}$ Department of Biomedical Science, College of Life Science, CHA University, Seongnam 13488, South Korea. ${ }^{2}$ Department of Obstetrics and Gynecology, CHA Bundang Medical Center, School of Medicine, CHA University, Seongnam 13496, South Korea. ${ }^{3}$ Department of Obstetrics and Gynecology, CHA Gangnam Medical Center, School of Medicine, CHA University, Seoul 06135, South Korea.

Received: 12 July 2019 Accepted: 17 October 2019 Published online: 16 December 2019

\section{References}

1. Polanski LT, Baumgarten MN, Quenby S, Brosens J, Campbell BK, RaineFenning NJ. What exactly do we mean by 'recurrent implantation failure'? A systematic review and opinion. Reprod Biomed Online. 2014;28(4):409-23.

2. Margalioth E, Ben-Chetrit A, Gal M, Eldar-Geva T. Investigation and treatment of repeated implantation failure following IVF-ET. Hum Reprod. 2006;21(12):3036-43

3. Tan BK, Vandekerckhove P, Kennedy R, Keay SD. Investigation and current management of recurrent IVF treatment failure in the UK. BJOG. 2005;112(6): 773-80.

4. Bartel DP. MicroRNAs: genomics, biogenesis, mechanism, and function. Cell. 2004;116(2):281-97.

5. Revel A, Achache H, Stevens J, Smith Y, Reich R. MicroRNAs are associated with human embryo implantation defects. Hum Reprod. 2011;26(10):283040.

6. Koler M, Achache H, Tsafrir A, Smith Y, Revel A, Reich R. Disrupted gene pattern in patients with repeated in vitro fertilization (IVF) failure. Hum Reprod. 2009;24(10):2541-8.

7. Liang J, Wang S, Wang Z. Role of microRNAs in embryo implantation. Reprod Biol Endocrinol. 2017;15(1):90.

8. Zygmunt M, Herr F, Münstedt K, Lang U, Liang OD. Angiogenesis and vasculogenesis in pregnancy. Eur J Obstet Gynecol Reprod Biol. 2003;110: S10-8.

9. Andraweera PH, Dekker GA, Roberts CT. The vascular endothelial growth factor family in adverse pregnancy outcomes. Hum Reprod Update. 2012; 18(4):436-57.

10. Vincenti V, Cassano C, Rocchi M, Persico MG. Assignment of the vascular endothelial growth factor gene to human chromosome 6p21. 3. Circulation. 1996;93(8):1493-5.

11. Boudjenah R, Molina-Gomes D, Wainer R, de Mazancourt P, Selva J, Vialard F. The vascular endothelial growth factor (VEGF) $+405 \mathrm{G} / \mathrm{C}$ polymorphism and its relationship with recurrent implantation failure in women in an IVF programme with ICSI. J Assist Reprod Genet. 2012;29(12):1415-20.
12. Goodman C, Jeyendran $\mathrm{R}$, Coulam C. Vascular endothelial growth factor gene polymorphism and implantation failure. Reprod Biomed Online. 2008; 16(5):720-3

13. Wu QB, Chen J, Zhu JW, Yin X, You HY, Lin YR, Zhu HQ. MicroRNA-125 inhibits RKO colorectal cancer cell growth by targeting VEGF. Int J Mol Med. 2018:42(1):665-73.

14. Su M-T, Lin S-H, Lee I-W, Chen Y-C, Kuo P-L. Association of polymorphisms/ haplotypes of the genes encoding vascular endothelial growth factor and its KDR receptor with recurrent pregnancy loss. Hum Reprod. 2011;26(4): 758-64.

15. Ferrara N. Vascular endothelial growth factor: basic science and clinical progress. Endocr Rev. 2004;25(4):581-611.

16. Thornton P, Douglas J. Coagulation in pregnancy. Best Pract Res Clin Obstet Gynaecol. 2010;24(3):339-52

17. De Moerloose $\mathrm{P}$, Casini A, Neerman-Arbez M: Congenital fibrinogen disorders: an update. In: Semin Thromb Hemost: 2013: Thieme Medical Publishers; 2013: 585-595.

18. Ambros V. The functions of animal microRNAs. Nature. 2004;431(7006):350-

19. Cho SH, Kim YR, Kim JH, An HJ, Kim JO, Ko JJ, Lee WS, Kim NK. The association of miR-25 T>C, miR-32C $>A$, miR-125C $>T$, and miR-222G $>T$ polymorphisms with a risk of primary ovarian insufficiency in Korean women. Menopause. 2019;26(4):409-16.

20. Jung YW, Jeon YJ, Rah H, Kim JH, Shin JE, Choi DH, Cha SH, Kim NK. Genetic variants in microRNA machinery genes are associate with idiopathic recurrent pregnancy loss risk. PLoS One. 2014;9(4):e95803.

21. Bidarimath M, Edwards AK, Wessels JM, Khalaj K, Kridli RT, Tayade C. Distinct microRNA expression in endometrial lymphocytes, endometrium, and trophoblast during spontaneous porcine fetal loss. J Reprod Immunol. 2015; 107:64-79.

22. Fort A, Borel C, Migliavacca E, Antonarakis SE, Fish RJ, Neerman-Arbez M. Regulation of fibrinogen production by microRNAs. Blood. 2010;116(14): 2608-15.

23. Tang F, Kaneda M, O'Carroll D, Hajkova P, Barton SC, Sun YA, Lee C, Tarakhovsky A, Lao K, Surani MA. Maternal microRNAs are essential for mouse zygotic development. Genes Dev. 2007;21(6):644-8.

24. Chu B, Zhong L, Dou S, Wang J, Li J, Wang M, Shi Q, Mei Y. Wu M: miRNA181 regulates embryo implantation in mice through targeting leukemia inhibitory factor. J Mol Cell Biol. 2015;7(1):12-22.

25. Ivanov P, Tsvyatkovska T, Konova E, Komsa-Penkova R. Inherited thrombophilia and IVF failure: the impact of coagulation disorders on implantation process. Am J Reprod Immunol. 2012;68(3):189-98.

26. Shi C, Shen H, Fan LJ, Guan J, Zheng XB, Chen X, Liang R, Zhang XW, Cui $\mathrm{QH}$, Sun KK, et al. Endometrial MicroRNA signature during the window of implantation changed in patients with repeated implantation failure. Chin Med J. 2017;130(5):566-73.

27. Altmae S, Martinez-Conejero JA, Esteban FJ, Ruiz-Alonso M, Stavreus-Evers A Horcajadas JA, Salumets A. MicroRNAs miR-30b, miR-30d, and miR-494 regulate human endometrial receptivity. Reprod Sci (Thousand Oaks, Calif). 2013;20(3):308-17

28. Sonderegger S, Pollheimer J, Knofler M. Wnt signalling in implantation, decidualisation and placental differentiation--review. Placenta. 2010;31(10):839-47.

29. Karami F, Askari M, Modarressi MH: Investigating association of rs5918 human platelets antigen 1 and rs1800790 fibrinogen beta chain as critical players with recurrent pregnancy loss. Med Sci (Basel, Switzerland) 2018, 6(4).

30. Kariyazono H, Ohno T, Khajoee V, Ihara K, Kusuhara K, Kinukawa N, Mizuno Y, Hara T. Association of vascular endothelial growth factor (VEGF) and VEGF receptor gene polymorphisms with coronary artery lesions of Kawasaki disease. Pediatr Res. 2004;56(6):953-9.

31. Zygmunt M: Angiogenesis and vasculogenesis in pregnancy and in tumor development. In: Cancer and Pregnancy. Springer; 2001: 251-266.

32. Çöl-Madendag I, Madendag Y, Altinkaya SÖ, Bayramoglu H, Danisman N. The role of VEGF and its receptors in the etiology of early pregnancy loss. Gynecol Endocrinol. 2014;30(2):153-6.

33. Hiratsuka S, Kataoka Y, Nakao K, Nakamura K, Morikawa S, Tanaka S, Katsuki M, Maru Y, Shibuya M. Vascular endothelial growth factor A (VEGF-A) is involved in guidance of VEGF receptor-positive cells to the anterior portion of early embryos. Mol Cell Biol. 2005;25(1):355-63.

34. Jang MJ, Jeon YJ, Kim JW, Cho YK, Lee SK, Hwang SG, Oh D, Kim NK. Association of VEGF and KDR single nucleotide polymorphisms with colorectal cancer susceptibility in Koreans. Mol Carcinog. 2013;52(S1):60-9. 
35. Dassoulas K, Gazouli M, Rizos S, Theodoropoulos G, Christoni Z, Nikiteas N, Karakitsos P. Common polymorphisms in the vascular endothelial growth factor gene and colorectal cancer development, prognosis, and survival. Mol Carcinog. 2009:48(6):563-9.

36. Lee HA, Ahn EH, Jang HG, Kim JO, Kim JH, Lee YB, Lee WS, Kim NK. Association between miR-605A>G, miR-608G $>C$, miR-6311 $>$ D, miR-938C $>T$, and miR-1302-3C>T polymorphisms and risk of recurrent implantation failure. Reprod Sci (Thousand Oaks, Calif). 2019;26(4):469-75.

37. Ubaldi F, Rienzi L, Baroni E, Ferrero S, lacobelli M, Minasi MG, Sapienza F, Martinez F, Cobellis L, Greco E. Implantation in patients over 40 and raising FSH levels--a review. Placenta. 2003;24(Suppl B):S34-8.

38. Robson A, Harris LK, Innes BA, Lash GE, Aljunaidy MM, Aplin JD, Baker PN, Robson SC, Bulmer JN. Uterine natural killer cells initiate spiral artery remodeling in human pregnancy. FASEB J. 2012;26(12):4876-85.

39. Sergent F, Hoffmann P, Brouillet S, Garnier V, Salomon A, Murthi P, Benharouga M, Feige JJ, Alfaidy N. Sustained endocrine gland-derived vascular endothelial growth factor levels beyond the first trimester of pregnancy display phenotypic and functional changes associated with the pathogenesis of pregnancy-induced hypertension. Hypertension. 2016;68(1): 148-56.

40. Chirshev E, Oberg KC, loffe YJ, Unternaehrer JJ. Let-7 as biomarker, prognostic indicator, and therapy for precision medicine in cancer. Clin Transl Med. 2019;8(1):24.

41. C-y Y. Zhang B, Ying C-m: Elevated serum level of IL-35 associated with the maintenance of maternal-fetal immune tolerance in normal pregnancy. PLoS One. 2015:10(6):e0128219.

42. Loewendorf Al, Nguyen TA, Yesayan MN, Kahn DA. Normal human pregnancy results in maternal immune activation in the periphery and at the uteroplacental interface. PLoS One. 2014;9(5):e96723.

43. Guerin $L R$, Prins JR, Robertson SA. Regulatory T-cells and immune tolerance in pregnancy: a new target for infertility treatment? Hum Reprod Update. 2009;15(5):517-35.

44. Aluvihare VR, Kallikourdis M, Betz AG. Regulatory T cells mediate maternal tolerance to the fetus. Nat Immunol. 2004;5(3):266-71.

45. Bansal R, Ford B, Bhaskaran S, Thum M, Bansal A. Elevated levels of serum vascular endothelial growth factor-A are not related to NK cell parameters in recurrent IVF failure. J Reprod Infertil. 2017;18(3):280-7.

46. Seshadri S, Sunkara SK. Natural killer cells in female infertility and recurrent miscarriage: a systematic review and meta-analysis. Hum Reprod Update. 2013;20(3):429-38

47. Rupaimoole R, Slack FJ. MicroRNA therapeutics: towards a new era for the management of cancer and other diseases. Nat Rev Drug Discov. 2017;16(3): 203-22.

48. Di Pietro C. Exosome-mediated communication in the ovarian follicle. J Ass Reprod Genet. 2016;33(3):303-11.

49. Lockshin MD, Kim M, Laskin CA, Guerra M, Branch DW, Merrill J, Petri M Porter TF, Sammaritano L, Stephenson MD. Prediction of adverse pregnancy outcome by the presence of lupus anticoagulant, but not anticardiolipin antibody, in patients with antiphospholipid antibodies. Arthritis Rheum. 2012:64(7):2311-8.

50. Middeldorp S, van Hylckama VA. Does thrombophilia testing help in the clinical management of patients? Br J Haematol. 2008;143(3):321-35.

51. Wang H, Wu S, Wu J, Sun S, Wu S, Bao W. Association analysis of the SNP (rs345476947) in the FUT2 gene with the production and reproductive traits in pigs. Genes Genom. 2018;40(2):199-206.

\section{Publisher's Note}

Springer Nature remains neutral with regard to jurisdictional claims in published maps and institutional affiliations.

Ready to submit your research? Choose BMC and benefit from:

- fast, convenient online submission

- thorough peer review by experienced researchers in your field

- rapid publication on acceptance

- support for research data, including large and complex data types

- gold Open Access which fosters wider collaboration and increased citations

- maximum visibility for your research: over $100 \mathrm{M}$ website views per year

At $\mathrm{BMC}$, research is always in progress.

Learn more biomedcentral.com/submissions 